\title{
Transport and health around the world
}

I recently attended two conferences, at oosite ends of the spectrum. The first, the $96^{\text {th }}$ annual Transportation Research Board (TRB) conference

(www.trb.org/AnnualMeeting/AnnualMeeting.aspx), had around 13,000 participants, mostly from North America; few attendees are interested in health, or even realise that transport affects health, but this awareness is growing exponentially. In contrast, the Active Living Research conference (http://activelivingresearch.org/annual-conference-2017) practised what it preached. Both this and the International Conference on Transport and Health (the $3^{\text {rd }}$ conference will be held in Barcelona in June 2017: www.tphlink.com/icth-2017---barcelona.html) aim to connect researchers, practitioners, policy-makers, and community members to learn from each other; help get research evidence translated into practice; and help academics to conduct policy- and practice-relevant research. While this journal remains primarily focussed on disseminating academic work by researchers, authors of manuscripts to this journal are now required to include at least one highlight point and one paragraph in the discussion that is of relevance to practitioners and/or policy-makers (or make a case to the editor why it is not [yet] aropriate to do so).

As ever, this volume contains papers dealing with a wide range of topics from almost every continent, but with recurrent themes aearing. Casas et al (2017) consider access to healthcare using travel time for patients in Cali, Colombia, who have been diagnosed with dengue fever (a mosquitoborne infection which can be serious). As might be expected, those living in the periphery of the city spent longer travelling than those living near the main transport corridor, close to the main healthcare centres. However, this was not only because of difficulties with access. Travel times were up to six times longer than travel from home to the nearest healthcare facility. It was not clear whether such patients were not at home when they sought care, or whether the facilities offered at their chosen destination were perceived to be better but men and more affluent patients travelled longer and were more likely to attend a more distant healthcare centre. Infection - or rather, prevention of epidemics - is also the focus of the paper by Arslan and Polat (2017). They use archive data to analyse the use of quarantine centres by the Ottoman Empire in the $19^{\text {th }}$ century to prevent the rapid transmission of cholera and plague by increasingly rapid modes of travel such as steam powered ships.

We are publishing a methodological cautionary tale. Ermagun and Levinson (2017) remind us that, particularly in cross-sectional studies, association does not mean causation. However, the analyses by Ermagun and Levinson do not necessarily mean that using public transport [transit] does not benefit individuals' health. Unlike randomised controlled trials of therapy, the counterfactual condition is seldom available for measurement in cross-sectional studies. As Bradford Hill stated in his famous lecture, consistency across a range of types of study designs and populations and coherence across a range of severity of related outcomes are two key considerations in assessing causality (Hill 1965). Badland et al (2017) point out that we need more longitudinal studies in the field of transport and health to deal with this. While not free from confounding, particularly selfselection, measurement of change in behaviour and change in outcomes provide more robust evidence of the temporal relationship, with the postulated cause known to precede the effect. Martin et al (2015) provided data on the impacts of a change in commuting mode on subsequent $\mathrm{BMI}$, and also provided some evidence of reversibility.

The health impacts of air pollution linked to transport are increasingly being recognised and this edition includes a number of novel papers in this area. Pollutant emissions from vehicles in three metropolitan areas accounted for one-third of Brazil's fine particulate $\left(\mathrm{PM}_{2.5}\right)$ emissions but as these (and concentrations) fall, an increasing proportion of particulates are coming from non-exhaust sources, including tyres [tires], brakes, road surfaces, and evaporative losses when refuelling. Although coarse particulate $\left(\mathrm{PM}_{10}\right)$ levels were within Brazilian regulations, they exceeded World Health Organisation guidance threefold. About 405 of light duty vehicles (e.g. cars) currently run on ethanol, while biodiesel is projected to account for $30 \%$ of Brazilian fuel by 2030 (Torres Pacheco et 
al, 2017). Traffic policemen in Rohtak city, India and in Bogotá, Columbia have been found to have a higher prevalence of respiratory symptoms, in the latter case associated with personal $\mathrm{PM}_{10}$ exposure (Ahlawat and Shukla, 2010; Estévez-García et al, 2013). Delhi is one of the most polluted cities in the world (Jain et al, 2016; Torres Pacheco, 2017). Respiratory and cardiovascular symptoms and diseases are also more common in traffic policemen in Delhi, India compared with office workers, increasing markedly with increased length of service duration (Bajaj et al, 2017). Cyclists' exposure to and inhaled dose of air pollution depend on the routes they choose (Bigazzi et al, 2016; Do Valea et al, 2015) although only in Warsaw have the negative impacts of air pollution been estimated to outweigh the physical activity benefits (Tainio, 2015). Pattinson and colleagues (2017) have quantified the effects on cyclists' exposure to pollution of their distance from road traffic. Both ultrafine particles and carbon monoxide exposure was 20-30\% lower at the pavement [sidewalk] and 40-50\% lower on an off-road path $19 \mathrm{~m}$ away. There was less effect on $\mathrm{PM}_{10}$ exposure. The authors posit that segregated pathways, often urged for safety reasons and to encourage cycling among less experienced cyclists, would also reduce pollutant intake.

There is overwhelming evidence of the health risks of inactivity and the benefits of physical activity (Ding et al, 2016; Sallis et al, 2016). If, as has been demonstrated (Besser and Dannenberg, 1965; Sener et al, 2016), individuals can achieve the minimum recommended physical activity through walking to and/or from public transport, then this is likely to benefit their health unless it replaces their previous activity regimen. Most studies that have examined that have not found substitution (eg Saelens et al, 2014). Even if substitution does occur, modal shift may benefit the wider community if it replaces car journeys, with the air and noise pollution and injury risk these journeys impose on other road users and local residents (Khreis et al, 2016).

Götschi and Loh (2017) modelled the potential health impacts of active travel on 14 trails in the USA. They point out inadequacies in previous work and include cautious monetisation, using the Trail Modeling and Assessment Platform (T-MAP). They point out that most trail users already have above average activity levels, so the health gains are less than would accrue if inactive people were to start using the trails. However, this study does not distinguish between active travel as a leisure activity itself and active travel as a means of transport to reach a desired destination. The former is the target for active living, the latter is the focus of transport planners, engineers, and researchers. Meehan and Whitfield (2017) have described how a Metropolitan Planning Organisation (MPO) in the USA has integrated the health impacts of transport [transportation] into its transport planning. By including health considerations, the MPO has also been able to use the Integrated Transport and Health Impact Modeling tool (ITHIM (Whitfield et al, 2017; based on Woodcock et al, 2009)). They demonstrate an increase in infrastructure for active travel and expect an increase in walking and cycling to follow. Investment in infrastructure may have differential effects. While in many high income, car-dominated countries, the majority of cycling is done by males (eg Brown et al, 2016), Aldred and Dales (2017) have shown that the gender imbalance in cycling is less on protected cycle routes than on cycle lanes and roads in London, UK. Cyclists on the protected routes were also less likely to wear helmets or sporty clothing, thus resembling more the aroach to cycling in countries where it is a dominant mode of transport.

Those concerned about the health impacts of transport are generally in favour of discouraging the use of private motor vehicles and advocate switching mode, ideally to walking or cycling but potentially also to public transport [transit], also referred to as active travel by some because of the potential for active travel at one or both ends of the journey. However, people living in remote or rural areas, or in the outskirts of urban areas with poor public transport access (Badland et al, 2017), may have little option but to drive in order to access important destinations, such as employment, education, healthcare, and shops. Transport disadvantage accrues particularly to the poor (Mackett and Thoreau, 2015); when a car is deemed essential, the expense of a car can be a particularly large proportion of their income ('transport poverty' (Gleeson and Randolph, 2002)), and the economic constraints lead to the use of older, more polluting cars (Torres Pacheco et al, 2017). 
Cullen et al (2017, Editor's choice) identified a particular problem in remote Aboriginal communities in Australia, where people were driving through the lack of other transport options, despite not having training nor a driving licence. This was associated with high injury risk (for themselves and others) and prison [jail] sentences for those caught driving without a licence or associated with lack of access to employment oortunities. They developed culturally-aropriate, flexible programmes to address barriers (such as the lack of a birth certificate, low literacy rates, cost of training, low availability of supervisory drivers) and facilitate training and licensing. Their programme targeted areas of high need, with positive effects seen in a dose-response manner.

In contrast, Cole and colleagues (2017) studied car trips in Australia that could be walkable. Using sex- and age-specific centiles, $7 \%$ were considered short enough to be walked. One potential adverse effect of more walking in some climates is an increase in heat exposure of pedestrians, which particularly affects disadvantaged communities in car-based societies (Karner et al, 2015). A switch to public transport [transit] could also increase exposure of passengers [riders] to excessive heat from walking to and waiting at public transport stops in hot climates, as Fraser and Chester (2017) point out from their study in the USA. Heat exposure will be a particular problem where there is urban sprawl and poor direct pedestrian access to public transport stops. Badland and colleagues (2017) also considered residential distance to public transport stops, in Melbourne, Australia. They found that adults with longer commuting times sat for longer and had poorer self-rated health, and urban residential areas more than $400 \mathrm{~m}$ from a bus, $600 \mathrm{~m}$ from a tram, or $800 \mathrm{~m}$ from a train stop had higher car ownership and longer commuting times: perhaps an unsurprising conclusion but one that may need to be shown to transport authorities, although the authors also point out the need to consider temporal as well as geographical aspects of public transport access (Adams et al, 2016).

Sun and colleagues (2017) also consider access to public transport. They have developed a 67-item audit tool (CURWAST) to assess the walking environment around metro stations in China. Safety fears focus on traffic, including e-motorcycles, but not crime, which is seldom a concern for pedestrians in China. The built and planted environment also feature in the audit tool, as do the nuisance and barrier effects of itinerant vendors. Many small alleys were found, providing increased pedestrian permeability Although the walking tool had acceptable reliability, the cycling audit tool did not; they felt this was due to the paucity of cycling in the city..

I have recently reluctantly declined to review a number of very interesting manuscripts on cycling because the journal name was the only, or almost the only, mention of health in the manuscript. I should like to remind prospective authors that this is the Journal of Transport and Health: we expect submitted manuscripts to address both, not just one, of these two areas. (I have received only one submission so far that addressed neither!)

\section{References}

Adams E.J., F.C. Bull, C.E. Foster (2016) Are perceptions of the environment in the workplace 'neighbourhood' associated with commuter walking? J. Transp. Health, 3 (4), 479-484.

Ahlawat P, V. Shukla (2010) Monitoring of air pollution and assessment of its risk on traffic policemen. J. Al. Nat. Sci., 2, 296-299.

Aldred R, Dales J. Diversifying and normalising cycling in London, UK: An exploratory study on the influence of infrastructure. J Transp Health. 4, 348-362.

http://dx.doi.org.libproxy.ucl.ac.uk/10.1016/i.jth.2016.11.002

Arslan A, Polat HA (2017) Travel from Europe to Istanbul in the 19th century and the Quarantine of Çanakkale. J Transp Health. 4, 10-17. http://dx.doi.org.libproxy.ucl.ac.uk/10.1016/j.jth.2017.01.003 
Badland H, RAchele JN, Roberts R, Giles-Corti B (2017) Creating and alying public transport indicators to test pathways of behaviours and health through an urban transport framework. $J$ Transp Health. 4, 208-215. http://dx.doi.org.libproxy.ucl.ac.uk/10.1016/i.jth.2017.01.007

Bajaj N, Sharma T, Suneja D, Jain S, Kumar P (2017) Determinants of respiratory and cardiovascular health effects in traffic policemen: A perception-based comparative analysis. J Transp Health. 4, 3039. http://dx.doi.org.libproxy.ucl.ac.uk/10.1016/j.jth.2016.12.003

Besser LM, Dannenberg AL (2005) Walking to public transit: steps to help meet physical activity recommendations. Am J Prev Med. 29(4):273-28. Transit system design and vulnerability of riders to heat. J Transp Health. 4, 273-280. http://dx.doi.org.libproxy.ucl.ac.uk/10.1016/j.jth.2016.07.005

Bigazzi AY, J Broach, J Dill (2016) Bicycle route preference and pollution inhalation dose: Comparing exposure and distance trade-offs. J Transp Health, 3 (1), 107-113.

Brown BB, D Tharp, CP. Tribby, KR. Smith, HJ. Miller, CM. Werner (2016) Changes in bicycling over time associated with a new bike lane: Relations with kilocalories energy expenditure and body mass index. J Transp Health, 3 (3), 357-365.

Casas I, Delmelle E, Delmelle EC (2017) Potential versus revealed access to care during a dengue fever outbreak. J Transp Health. 4, 18-29.

http://dx.doi.org.libproxy.ucl.ac.uk/10.1016/i.jth.2016.08.001

Cullen P, chevalier A, Hunter K, Gadsden T, Ivers R (2017) 'The program was the solution to the problem': Process evaluation of a multi-site driver licensing program in remote communities. $J$ Transp Health. 4, 81-89. http://dx.doi.org.libproxy.ucl.ac.uk/10.1016/i.jth.2016.07.004 (Editor's Choice)

Ding D, Lawson KD, Kolbe-Alexander TL, Finkelstein EA, Katzmarzyk PT, van Mechelen W, Pratt M, for the Lancet Physical Activity Series 2 Executive Committee (2016) The economic burden of physical inactivity: a global analysis of major non-communicable diseases. Lancet http://dx.doi.org/10.1016/S0140-6756(16)30383-X

Ermagun A, Levinson D (2017). "Transit makes you short": On health impact assessment of transportation and the built environment. J Transp Health. 4, 373387.http://dx.doi.org.libproxy.ucl.ac.uk/10.1016/j.jth.2016.08.004

Estévez-García JA, N.Y. Rojas-Roa, A.I. Rodríguez-Pulido (2013) Occupational exposure to air pollutants: particulate matter and respiratory symptoms affecting traffic-policemen in Bogota. Rev. Salud Publica, 15, . 889-902.

Fraser AM, Chester MV (2017) Transit system design and vulnerability of riders to heat. J Transp Health. 4, 216-225. http://dx.doi.org.libproxy.ucl.ac.uk/10.1016/j.jth.2016.07.005

Gleeson B, Randolph B (2002) Social Disadvantage and Planning in the Sydney Context. Urban Policy and Research 20(1):101-107. DOI: 10.1080/08111140220131636

Götschi T, Loh TH (2017) Advancing project-scale health impact modeling for active transportation: A user survey and health impact calculation of 14 US trails. J Transp Health. 4, 334-347.

http://dx.doi.org.libproxy.ucl.ac.uk/10.1016/i.jth.2017.01.005

Hill AB (1965) The Environment and Disease: Association or Causation? Proc R Soc Med. 58(5): 295300.

Jain S, P. Aggarwal, P. Sharma, P. Kumar (2016) Vehicular exhaust emissions under current and alternative future policy measures for megacity Delhi, India. J. Transp. Health, 3, . 404-412.

Karner A , DM. Hondulab, J K. Vanosc (2015) Heat exposure during non-motorized travel: Implications for transportation policy under climate change. J Transp Health, 2 (4), 451-459. 
Khreis H, KM. Warsow, EVerlinghieri, A Guzman, L Pellecuer, A Ferreira, I Jones, E Heinen, D RojasRueda, N Mueller, P Schepers, K Lucas, MNieuwenhuijsen (2016) The health impacts of trafficrelated exposures in urban areas: Understanding real effects, underlying driving forces and coproducing future directions. J Transp Health, 3 (3), 249-267.

Mackett RL, R Thoreau (2015) Transport, social exclusion and health. J Transp Health, 2 (4), 610-617

Martin A, Panter J, Suhrcke M, Ogilvie D, (2015) Impact of changes in mode of travel to work on changes in body mass index: evidence from the British household panel survey. J. Epidemiol. Community Health. 69, 753-761 http://dx.doi.org/10.1136/jech-2014-205211

Ministry of Transport, 2009. Cycling in the Netherlands. Ministry of Transport, Public Works and Water Management, Directorate-General for Passenger Transport and Fietsberaad, Expertise Centre for Cycling Policy, Den Haag and Utrecht.

Meehan LA, Whitfield GP. Integrating health and transportation in Nashville, Tennessee, USA: From policy to projects. J Transp Health. 4, 325-333.

http://dx.doi.org.libproxy.ucl.ac.uk/10.1016/i.jth.2017.01.002

Pattinson W, Kingham S, Longley I, Salmond J (2017) Potential pollution exposure reductions from small-distance bicycle lane separations. J Transp Health. 4, 40-52.

http://dx.doi.org.libproxy.ucl.ac.uk/10.1016/i.jth.2016.10.002

Saelens BE, Moudon AV, Kang B, Hurvitz PM, Zhou C, (2014). Relation between higher physical activity and public transit use. Am. J. Public Health. 104 (5), 854-859

Sallis JF, Bull F, Guthold R, Heath GW, Inoue S, Kelly P, Oyeyemi AL, Perez LG, Richards J, Hallal PC, for the Lancet Physical Activity Series 2 Executive Committee (2016) Progress in physical activity over the Olympic quadrennium. Lancet http://dx.doi.org/10.1016/S0140-6736(16)30581-5

Sener IN, Lee RJ, Elgart Z (2016) Potential health implications and health cost reductions of transitinduced physical activity. J. Transp. Health, 3 (2) . 133-140

Sun G, Webster C, Chiaradia A (2017) Objective assessment of station approach routes:

Development and reliability of an audit for walking environments around metro stations in China. $J$ Transp Health. 4, 191-207. http://dx.doi.org.libproxy.ucl.ac.uk/10.1016/i.jth.2017.01.010

Tainio M (2015) Burden of disease caused by local transport in Warsaw, Poland. J Transp Health Volume 2, Issue 3, 423-433

Torres Pacheco M, Miotto Parmigiani MM, dre Fatima Andrade M, Morawski L, Kumar P (2017) A review of emissions and concentrations of particulate matter in the three major metropolitan areas of Brazil. J Transp Health. 4, 53-72. http://dx.doi.org.libproxy.ucl.ac.uk/10.1016/i.jth.2017.01.008

Do Valea ID, Ana S. Vasconcelosb, Gonçalo O. Duartea, (2015) Inhalation of particulate matter in three different routes for the same OD pair: A case study with pedestrians in the city of Lisbon. $J$ Transp Health, 2 (4), 474-482.

Whitfield GP, Meehan LA, Maizlish N, Wendel AM (2017) The integrated transport and health impact modeling tool in Nashville, Tennessee, USA: Implementation steps and lessons learned. J Transp Health. In press, http://dx.doi.org.libproxy.ucl.ac.uk/10.1016/i.jth.2016.06.009

Woodcock J, Edwards P, Tonne C, Armstrong BG, Ashiru O, Banister D, et al. (2009) Public health benefits of strategies to reduce greenhouse-gas emissions: urban land transport. Lancet, 374 (9705) (2009 05), 1930-1943. 